\title{
Male Allocare in Rhinopithecus bieti at Xiaochangdu, Tibet: Is It Related to Energetic Stress?
}

\author{
XIANG Zuo-Fu ${ }^{1,2, *}$, HUO Sheng ${ }^{2,3}$, XIAO Wen ${ }^{2,3}$ \\ (1. College of Life Science and Technology, Central South University of Forestry \& Technology, Changsha Hunan 410004, China; \\ 2. Kunming Institute of Zoology, the Chinese Academy of Sciences, Kunming Yunnan 650223, China; \\ 3. Institute of Eastern-Himalaya Biodiversity Research, Dali University, Dali Yunnan 671000, China)
}

\begin{abstract}
Male allocare among nonhuman primates has frequently been investigated from the perspective of the caretaker. Here we examined whether male allocare relates to environmental factors or the females' energetic stress. We researched the possible differences of allocare between sexes in free-ranging black-and-white snub-nosed monkeys (Rhinopithecus bieti) in Tibet. A combination of stepwise least squares regression analysis was used to identify the influence of ecological factors (temperature, rainfall, etc.) and infant age that best account for seasonal variation of allocare. The results indicate, except for the functions of infant age, however, that male allocare is a negative function of temperature and female allocare is a positive function of temperature. Specifically, we tested the energetic stress hypothesis, which predicts that the energetic burden of females in a severe environment favour an increased rate of male allocare during the seasons of high energetic stress. We analyzed the allocare difference between high energetic stress season (Mar - Apr), when temperature was low, food availability was scarce, and infants were young, and low energetic stress season (Jun - Aug), based on data obtained during June 2003 - June 2004. Our results supported the energetic stress hypothesis because male allocare in high energetic stress season was higher than that of in low energetic stress season and female allocare was reverse. Therefore, we propose it is the energetic stress on female that make male allocare possible. Male take these interests for other aims and meet some functional hypothesis, which are addressed from the perspective of the male.
\end{abstract}

Key words: Parental investment; Intensive male infant caretaking; Energetic stress hypothesis; Colobinae

\section{西藏小昌都黑白仰鼻猴的雄婴照料：能量胁迫导致？}

\author{
向左甫 ${ }^{1,2}, *$, 霍 晟 ${ }^{2,3}$, 肖 文 ${ }^{2,3}$ \\ (1. 中南林业科技大学 生命科学与技术学院, 湖南 长沙 410004; 2.中国科学院昆明动物研究所, 云南 昆明 650223 ; \\ 3. 大理学院 东喜玛拉雅资源与环境研究所, 云南 大理 671000)
}

摘要: 雄猴照料贞猴行为通常都是从雄猴的角度来分析该行为具有何种适应功能, 很少有研究关心为什么雌 猴会让雄猴参与照料活动。该文通过西藏小昌都黑白仰鼻猴群的系统观察取样, 采用回归分析雄婴照料行为季节 变动与贞猴年龄及生态因子 (环境温度、食物供应) 之间的关系, 试图分析是否由于能量胁迫导致雌猴让雄猴参 与照料活动, 并通过分析高能量胁迫季节 (环境温度低、食物缺乏, 婴猴年幼需要雌猴携带多) 与低能量胁迫季 节 (环境温度高、食物丰富, 婴猴年长需要雌猴携带少) 雄贞照料行为差异检验了能量胁迫假说。结果表明雄贞 照料行为与温度呈负相关函数, 而雌猴照料婴猴行为与温度呈正相关函数; 在高能量胁迫的季节, 雄猴参与照料 行为多, 而在低能量胁迫的季节雄猴照料行为少。因此, 作者认为是能量胁迫迫使雌猴放弃部分照料贞猴的机会, 雄猴利用照料机会获得了其他利益。

关键词: 父系投资; 强烈的雄婴照料; 能量胁迫假说; 疮猴

中图分类号: Q959.848; Q958.11 文献标志码: A 文章编号: 0254-5853-(2010)02-0189-09

\footnotetext{
Received date: 2009-10-10; Accepted date: 2010-02-24

Foundation items: The Innovation Project of the Chinese Academy of Sciences (grants KSCX2-1-03, KSCX2-1-09); the National Natural Science Foundation of China (30870375)
}

收稿日期：2009-10-10；接受日期：2010-02-24

基金项目：中国科学院知识创新工程项目（KSCX2-1-03, KSCX2-1-09); 国家自然基金（30870375）

*通讯作者 (Corresponding author), Tel: 0731-85623392, E-mail: zorph@126.com

第一作者简介: 向左甫 (1973 -), 博士, 副教授, 主要从事非人灵长类行为生态与保护生物学研究 
Most anthropoid primates are slow to develop, their offspring are mostly single births, and the inter-birth periods are long. To maintain a successful breeding, it is true that the infant must be care carefully by the mother or other troop members. Unlike males of many monogamous birds and mammalian carnivores (see Kleiman, 1977), male primates are generally precluded from helping the female with the activity of feeding the young. Among primates, males mostly assist with transporting infants and caring for them (e.g. grooming, observing while away from the mother). However, there are tremendous interspecies variations in male-infant interactions, ranging from extensive maternal-like care in marmosets to infanticide or mistreatment of infants in langurs (Hrdy, 1976). In an evolutionary perspective, there may be many trade-offs between the participators (i.e. mothers, males and infants). To explain these trade-offs, one must investigate two questions: why do males devote time and energy to care for infants, and why are mothers prepared to allow males to care for their infants given the risk of abuse?

The evolution of male allocare has typically been addressed from the perspective of the male (reviews in Hrdy, 1976; Mckenna, 1979; Riedman, 1982; Emlen, 1991). Several hypotheses have been put forward to explain male allocare or male infant interactions in nonhuman primates based on adaptive theory such as kin selection (Hamilton, 1964) and sexual selection theory:

(1) The 'paternal investment hypothesis' proposes that males invest in their own progeny or otherwise related infants (Taub, 1984; for a review see van Schaik \& Paul, 1996). According to Hamilton's kin selection theory, care-giving behavior is only adaptive if the caregiver is related to the infant. A modified version of the paternal investment hypothesis is that fathers may be protective of putative offspring because other males are aggressive to them: the 'infanticide hypothesis' (for a review see Paul et al, 2000). If infants are under threat from males that 'invade' groups, then putative fathers should be protective of infants, and aggressive to outside males.

(2) The 'mating effort hypothesis' proposes that males care for infants to increase their access to mothers and increase chances of mate acquisition (Smuts, 1985). Also, there is an adaptive theory based on other causes, the 'agonistic buffering' hypothesis proposes that males do not really care for infants but use them in triadic male-infant-male interactions (Deag \& Crook, 1971; for a review see Paul et al, 2000). This hypothesis assumes that males use infants in triadic interactions to stabilize or regulate relationships with other males and particularly to reduce aggressions with other males.

Previous research on male allocare among primates has focused primarily on why male care for infants or whether the male benefits from infant care. However, the question, why mothers permit male care of infants, while male may be less solicitous towards infants or less competent carer than the mothers, has seldom been addressed. The mother should allow male allocare only if the benefit to her outweighs the potential costs of relinquishing an infant to the male. There are a number of possible reasons why the balance of such a cost: benefit equation might result in mothers allowing male care for their infant. Mothers may gain energetically from allocare if males care for their infants for a significant length of time. Energetic gains might arise either because mothers have to expend less energy on carrying young or if allocare allows them feed for longer or more efficiently (Hrdy, 1976; Sommer, 1989; Stanford, 1992). These energetic advantages will offer reproductive advantages if the saving of energetic expenditure or increased feeding ability either increases infant survival rates and/or increase maternal reproductive rates.

There are four processes that mainly determine the expenditure of energy for an animal: basal metabolism rate (BMR), active metabolism, growth and reproduction (Dunbar, 1988). BMR is also partly determined by the costs of thermoregulation, i.e., when the ambient temperature drops substantially below its normal body temperature, energy has to be expended to maintain its normal value. Nakayama et al (1971) reported that the energy expenditure of outdoor-living captive Japanese macaques at $5.2^{\circ} \mathrm{C}$ is 2.5 times larger than that at $29.5^{\circ} \mathrm{C}$. The active metabolic requirement reflects the fact that any activity over and above resting requires additional energy to fuel it. The quantity of additional energy depends on the amount of work being done. Energy consumption increases linearly with the load being carried (i.e. carry infant) (Taylor et al, 1982). For an adult female, the energy demand for growth is relatively low compared to an immature one; but the energy of reproduction is most pronounced. After fertilization has occurred, gestation imposes an increased energy demand on the female, with an energy requirement that is about $25 \%$ above normal during the second half of pregnancy; lactation adds to this burden, requiring an energy intake approximately $50 \%$ higher than normal (see Dunbar, 1987). The energy expended for maintaining body 
temperature and reproduction has to be obtained by consuming more food (or foods of a higher energetic value). In general, in order to get more food it is necessary to increase the time devoted to feeding. This strategy is adopted by wild gelada baboons (Iwamoto \& Dunbar 1983) and Barbary macaque (Fa, 1986). However, as more time devoted to feeding less time is available for infant care, which creates urgency for male allocare to meet female needs. The energetic stress hypothesis being tested is whether when females face high energetic stress during periods of low ambient temperature, scarcity of food, and when infants are still carried and nursed by the mother, then a higher male allocare is predicted; or when under more favorable environmental conditions, then male allocare is expected to drop. Otherwise, the economic allocare category (i.e., guarding, see methods) is predicated higher in high energetic stress season than in low energetic stress season.

Here, we hypothesize that it is energetic stress factors (physiological and environmental) that make mothers permit male care infant. We also attempted to ground it by using the observation data in the black-and-white snub-nosed monkey (Rhinopithecus bieti) at Xiaochangdu, Tibet, among the most unusual habitat for primates due to its high elevation (3500$4250 \mathrm{~m} \mathrm{asl}$ ) and extremely cold climate (as low as -15 ${ }^{\circ} \mathrm{C}$ in winter).

\section{Materials and Methods}

\subsection{Study site and subjects}

We carried out our study at Xiaochangdu $\left(29^{\circ} 15^{\prime} \mathrm{N}\right.$, $\left.98^{\circ} 37^{\prime} \mathrm{E}\right)$ in Honglaxueshan National Nature Reserve (HNNR), southeast of Tibet. HNNR comprises approximately 185300 hectare, and contains mainly primary conifer forests with mosaic evergreen broadleaf forests (for detailed descript, see Xiang et al, 2007a). The annual precipitation is $740 \mathrm{~mm}$, and the mean annual temperature is $4.7^{\circ} \mathrm{C}$ (from March 2004 to February 2005). The monthly variation in precipitation and temperature is presented in Fig. 1. Days that average temperature $>10^{\circ} \mathrm{C}$ is 96 , days that average temperature $<0^{\circ} \mathrm{C}$ is 108 , months that the monthly mean temperature below $0^{\circ} \mathrm{C}$ is four.

Black-and-white snub-nosed monkeys (Rhinopithecus bieti) belong to the Colobinae (Elliot, 1912), and occur only in northwest Yunnan and southeast Tibet, China. A tiny geographic area bounded by the upper Yangtze River to the east and the upper Mekong River to the west, between Zhina $\left(29^{\circ} 22^{\prime} \mathrm{N}\right.$, Xiang et al, 2007a) and Mt. Longma $\left(26^{\circ} 14^{\prime} \mathrm{N}\right.$, Long et al, 1994). The study group at Xiangchangdu, with about 210 individuals, is located in the northernmost part of the species' distribution, and mainly ranged between 3500 and 4250 $\mathrm{m}$ asl (Xiang, 2005). The basic social unit is based on multi-female, one-male units (OMU, Kirkpatrick et al, 1998), and a few multi-female, multi-male units (Ding et al, 2004). Breeding is seasonally restricted and almost synchronous; females give birth only during the period of early February to mid March, which marks the end of the severe winter (Xiang \& Sayers, 2009). The Monkeys feed on lichens year-round. In general, besides lichens, the diet becomes more abundant from May, when there are buds, young leaves and flowers; but abundance decreases abruptly after September, when diet consists of bark and dried herbs (Xiang et al, 2007b). It is difficult to identify individual animals due to the large group size; the age/sex classes of the animals were assigned based on body size, coat color and other traits (Tab. 1).

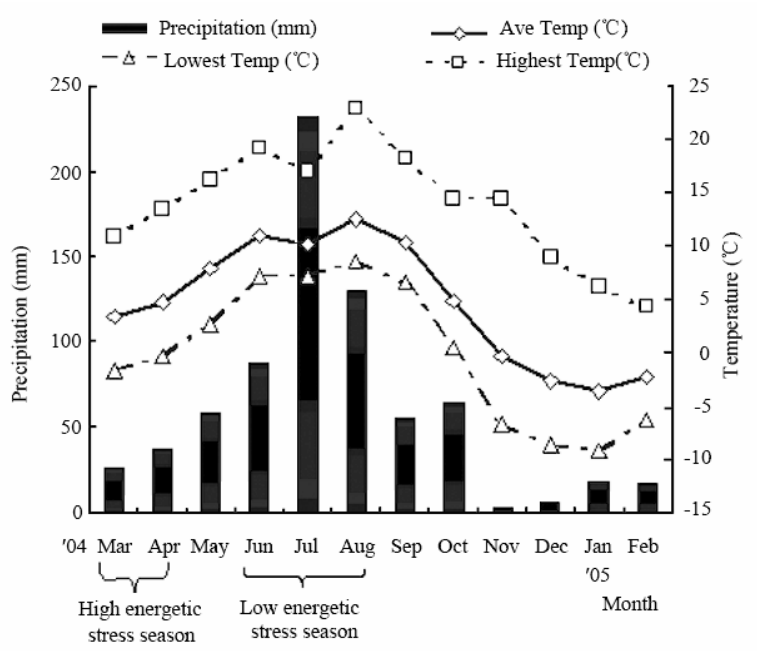

Fig. 1 Monthly precipitation ( $\mathrm{mm}$ ) and monthly lowest, mean and highest temperatures $\left({ }^{\circ} \mathrm{C}\right)$ at Xiaochangdu, Tibet Show the high energetic stress and low energetic season. Data collected at $3800 \mathrm{~m}$ asl from March 2004 to February 2005.

\subsection{Data collection}

Due to the rough terrain and dense forest, most observations took place at distances between $50-500 \mathrm{~m}$ from the study subjects with help of a field scope Nikon EDII $(20-56 \times)$ or binoculars $(10 \times)$ if necessary. We usually positioned ourselves at opposite slopes, although approaches to about $15-20 \mathrm{~m}$ were sometimes feasible. We approached the monkeys for the principal purpose of getting more detailed insights into the infant care behavior from time to time. We applied instantaneous 
Tab. 1 Features used to tell apart the age/sex classes in Rhinopithecus bieti, modified from Kirkpatrick (1996)

\begin{tabular}{|c|c|}
\hline Age/Sex class & Traits \\
\hline Adult male (M) & $\begin{array}{l}\text { Largest individuals of the band. Long white hair on flanks obscures ischial callosities, strong contrast of black and } \\
\text { white hair, hair on top of head falls forward, tail long and bushy. }\end{array}$ \\
\hline Adult female (F) & $\begin{array}{l}\text { Large individuals. Body length }(\mathrm{BL}) \leqslant 1 / 2 \mathrm{M} \text {. Short white hair on flanks, ischial callosities visible, contrast of } \\
\text { black-grey and white hair weaker than in males, hair on top of head in a "top-knot", tail gracile (relative to males). } \\
\text { Black nipples contrast with white chest hair. }\end{array}$ \\
\hline Sub-adult male (Sm) & $\begin{array}{l}\text { This is a special class in the band. } \mathrm{F} \leqslant \mathrm{BL} \leqslant \mathrm{M} \text {. In general, they are excluded from OMUs, and stroll between } \\
\text { OMUs, or form all male units. The contrast of hair is clearer and hair is longer than in females. }\end{array}$ \\
\hline Juvenile (J) & Medium-sized individuals. $\mathrm{I} \leqslant \mathrm{BL} \leqslant \mathrm{F}$. Back and limbs light grey. Tail hair short. \\
\hline Infant (I) & Smallest individuals of band. $\quad$ BL $\leqslant$ J. Coat bright white when new born, and later with light grey on the back. \\
\hline
\end{tabular}

scan sampling (Altman, 1974) at 15 min intervals: once an infant appeared, we observed it for at least $5 \mathrm{~s}$ and identified both the caretaker and the care category. We collected data from June 2003 to June 2004. We could observe the monkeys every day during fieldwork with two exceptions: (1) in September, thick fog made observations difficult, and human activity while searching for the mushroom (Tricholoma bakamatsutake) and does not allow us to observe them without disturbing them; (2) in January and February, observation conditions were unfavorable due to a thick snow layer (40 $-80 \mathrm{~cm}$ in depth) that inhibited progress (attempts were made once every $2-5 \mathrm{~d}$ to identifying births).

We defined three exclusive categories of infant care: (1) body contact, i.e., infant was carried, groomed or nursed; (2) in proximity, i.e., the caretaker was located around the infant, the distance between the caretaker and the infant is less than three times the body length (TBL) of the caretaker. TBL supposed that the caretaker could get to the infant easily if threatened. Only one infant was being cared in this way. If there was more than one caretaker who was located in less than TBL around the infant, we extended the observation time to two minutes to identify the true caretaker. If we were unable to achieve this within two minutes, we allocated the caretaker to uncertainty; (3) guarding, i.e., there were two or more than two infants playing together, and only one caretaker guards them in a protruding position. In this case, the infants were supposed to be in a crèche and an economic allocare category. Such crèches were usually found on the foliage, and the caretaker sat above it or nearby, where he could easily see every infant. The standard of guarding was whether the caretaker had a watching or vigilant behavior. In this case, even if there was an infant within TBL, we did not consider it as in proximity; this was due to the fact that with an increasing number of infants, the care provided to every infant decreased. Also, if we were unable to achieve this within two minutes, we allocated the caretaker to uncertainty.

\subsection{Data analysis}

Allocare records for different category and caretaker were first calculated as proportions of the monthly allocare time to reduce biases resulting from unequal sample size. These calculations yielded a monthly allocare value in each care categories by each caretaker. A total monthly allocare of each caretaker was obtained by sum the values of three categories. Yearly value was obtained by averaging the monthly value. As the juvenile allocare of both sexes was common in Colobinae (Hrdy, 1976; Quiatt, 1979; Nicolson, 1987), we did not analyze the juvenile allocare. With a very clumped birth season of the animal, we used months old as infant age, for example infants in April were 2 months old, infants in June were 4 months old etc, in regression analysis. Data on food availability was estimated/ collected according to the method of Xiang et al (2007b). As we were interested only in evaluating the variation of food availability, plant parts that had not been eaten or had not shown a monthly variation (i.e., lichens, barks, etc) were not included in the calculation of the food availability scores.

A combination of stepwise least squares regression analysis was used to determine the ecological factors and infant age that best account for seasonal variation of allocare. All equations were assessed to ensure that the variables incorporated into the final models were both statistically and computationally independent. All tests are two-tailed, with the level for significance set at default levels $P<0.05$ for inclusion and $P>0.05$ for exclusion from the models.

As mentioned above, ambient temperature, food availability and the stage of infant development are mainly determinants of energetic stress. Therefore, we also analyzed the allocare difference between high energetic stress season (March and April), when temperature was low and food was scarce, females were 
in lactation and had to carry their offspring frequently, and the low energetic stress season (June to August), when temperature was higher and food was easier to find, even females were still lactating and occupied with infant carrying. In order to relieve the error, we did not use the data obtained in May for it is difficult to distinguish the effect of food availability and temperature rising, and October to December because in these months there is food available and the infant can move independently without other members' help despite the temperatures remaining low. Statistical analyses were performed using the $\chi_{c}{ }^{2}$ contingency table analysis (Yate's corrections) to assess the difference in allocare frequencies/percent during the high and low energetic stress season, and Pearson correlation to identify relations among caretakers (Zar, 1999).

\section{Results}

Among $R$. bieti, troop member of all age and sex categories are involved with infants. Some individuals are true allocare in that they carry and care infants for a long period (Xiang et al, 2009). Of 1718 scans (429.5 h), we got 3608 infant samples (Tab. 2). The average infant in each scan is $3.39(S D=1.94$; range $0-8)$.

\subsection{Allocare (\%) of different caretaker and the rela- tions among them}

Yearly male allocare is $17.2 \%(S D=3.3 \%$; range $11.0 \%-21.8 \%$ ) with $0.6 \%$ body contact $(S D=0.5 \%$; range $0-1.5 \%), 5.8 \%$ in proximity $(S D=1.2 \%$; range $4.4 \%-7.9 \%)$ and $10.8 \%$ guarding $(S D=3.8 \%$; range $4.7 \%-16.8 \%$ ). Monthly male allocare of three categories and total are display in Fig. 2a. The lowest and highest

Tab. 2 Observation time and infant sample monthly

\begin{tabular}{clccc}
\hline Year & Month & Infant samples $^{\text {a }}$ & Numbers of scan & Hours \\
\hline 2003 & June & $311(7)$ & 139 & 34.75 \\
& July & $915(10)$ & 388 & 97 \\
& August & 254 & 147 & 36.275 \\
& October & $98(4)$ & 48 & 12 \\
& November & 363 & 208 & 52 \\
& December & 271 & 205 & 51.25 \\
\hline 2004 & March & $569(7)$ & 185 & 46.25 \\
& April & 289 & 120 & 30 \\
& May & 330 & 159 & 39.75 \\
& June & 208 & 119 & 29.75 \\
\hline Total & 3608 (28) & 1718 & 429.25 & \\
\hline${ }^{a}$ Uncertainty infant samples are given in parentheses. & &
\end{tabular}
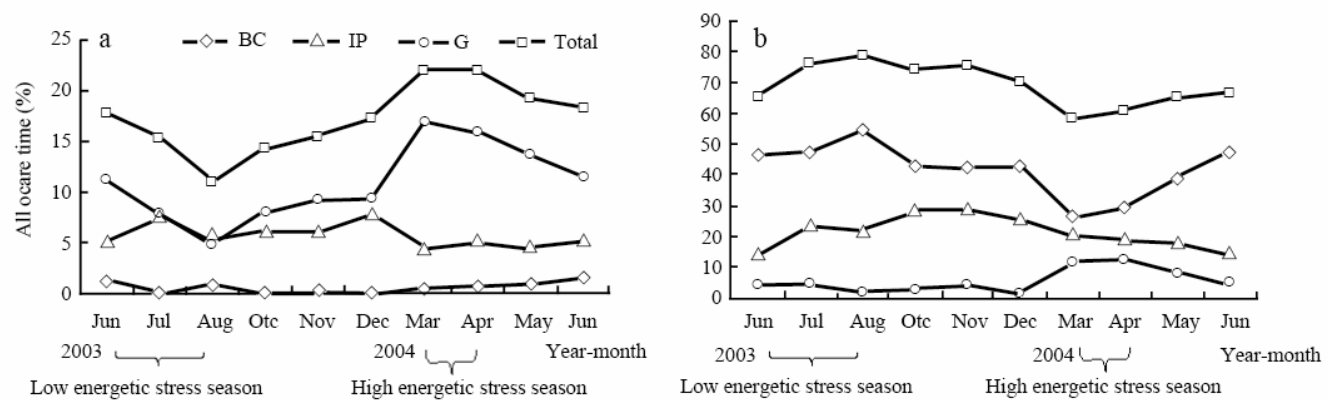

Fig. 2 Allocare (\%) in three categories of Rhinopithecus bieti at Xiaochangdu from June 2003 to June 2004 in monthly intervals

a: male allocare; b: female allocare;BC: means body contact allocare; IP: means in proximity allocare; G: means guarding allocare (see methods for detailed definition).

male allocare of guarding occur in August and March, respectively.

Yearly female allocare is $69.3 \%(S D=6.9 \%$, range $58.77 \%-78.7 \%)$ with $42.0 \%$ body contact $(S D=8.6 \%$; range $26.47 \%-54.7 \%), 21.6 \%$ in proximity $(S D=5.3 \%$; range $14.27 \%-28.9 \%)$ and $5.7 \%$ guarding $(S D=3.8 \%$; range $2.07 \%-12 \%$ ). Monthly female allocare of three categories and total are display Fig. 2b. The lowest 
female allocare of body contact and the highest female allocare of guarding occur simultaneously in March.

Male allocare is negative correlated to female allocare $\left(R_{p}=-0.95, N=10, P<0.001\right)$. The lowest female allocare and the highest male allocare occur simultaneously in March.

\subsection{Least square regression equations of allocare in ecological factors and infant age}

Tab. 3 displays the least square regression equations of ecological factors and infant ages on allocare. A consistent feature of the equations is that all models contain infant age and temperature. In the male allocare equation contain negative functions of temperature and infant age, but in female allocare equation are positive functions of temperature and infant age. These indicate differential influence of the environmental factors on the male and the female's allocare.

\subsection{Allocare difference between high and low ener-}

\section{getic stress seasons}

The results of male/female allocare frequency or percentage in high and low energetic stress season are shown in Tab. 4. There are significance differences of total male/female allocare and guarding care category between two seasons. These indicate energetic stresses on female and make male allocare possible.

\section{Discussion}

As individuals could not be identified and only one group provided data, conclusions must be drawn carefully. As we cannot identify the relative among infants and caretaker, we also cannot draw firm conclusion on some functional explanations (such as paternity, mate attraction, or agonistic buffering). But by using proper observation and analysis method, we did outline the allocare and its variation with environmental factor in $R$. bieti, a colobine that lives in an extremely seasonal variation climate with a longer snow cover. We also give a glimpse on explaining the diversity pattern of male allocare based on why the mothers permit the other care the infant. These mean males take the advantage of the female's energetic stress, and other ultimate explanations about male allocare may meet any

Tab. 3 Stepwise linear regression equation of infant age and environmental variables (temperature, food availability, rainfall) on the allocare component of Rhinopithecus bieti at Xiaochangdu

\begin{tabular}{lllllc}
\hline \multicolumn{1}{c}{ Allocare component $(\%)$} & \multicolumn{1}{c}{ Equation } & $R^{2}$ & $d f$ & $F$ & $P$ \\
\hline Male allocare $(M)$ & $M=25.89-1.09 I A-0.48 T$ & 0.84 & 2,7 & 18.45 & $\mathbf{0 . 0 0 2}$ \\
Male G allocare $(M \mathrm{~g})$ & $M \mathrm{~g}=21.04-1.32 I A-0.53 T$ & 0.96 & 2,7 & 38.97 & $\mathbf{0 . 0 0 0}$ \\
Female allocare $(F)$ & $F=52.48+2.29 I A+0.772 T$ & 0.81 & 2,7 & 14.69 & $\mathbf{0 . 0 0 3}$ \\
Female BC allocare $(F \mathrm{bc})$ & $F \mathrm{bc}=17.99+0.68 I A-1.59 T$ & 0.98 & 2,7 & 80.42 & $\mathbf{0 . 0 0 0}$ \\
Female G allocare $(F g)$ & $F \mathrm{~g}=15.58-1.37 I A-0.43 T$ & 0.96 & 2,7 & 40.59 & $\mathbf{0 . 0 0 0}$ \\
\hline
\end{tabular}

$T=$ Temperature, $I A=$ infant age (months). Number in bold indicate significant regressions. Order of independent variables in equations reflections relative importance as indicated by size of standardized coefficient. BC means body contact care; $\mathrm{G}$ means guarding care (see methods for detailed definition).

Tab. 4 Care frequency and male/female allocare during high energetic and low energetic stress seasons of Rhinopithecus bieti at Xiaochangdu, Tibet

\begin{tabular}{|c|c|c|c|c|c|}
\hline Caretaker & Category & High energetic stress season $(N=58)$ & Low energetic stress season $(N=1688)$ & $\chi_{\mathrm{c}}^{2 *}$ & $P$ \\
\hline \multirow{4}{*}{ Male } & $\mathrm{BC}$ & $5(0.6)$ & $9(0.5)$ & 0.02 & 0.9016 \\
\hline & IP & $40(4.7)$ & $110(6.5)$ & 3.2 & 0.0735 \\
\hline & G & $142(16.6)$ & $142(8.4)$ & 37.2 & 0.0000 \\
\hline & Total & $187(21.9)$ & $261(15.4)$ & 15.3 & 0.0000 \\
\hline \multirow{4}{*}{ Female } & $\mathrm{BC}$ & $234(27.3)$ & $818(48.5)$ & 104.44 & 0.0000 \\
\hline & IP & $174(20.3)$ & $348(20.6)$ & 0.02 & 0.8833 \\
\hline & G & $102(11.9)$ & $73(4.3)$ & 49.66 & 0.0000 \\
\hline & Total & $510(59.4)$ & $1239(73.4)$ & 50.9 & 0.0000 \\
\hline
\end{tabular}

$\mathrm{Ni}$ : the sample size. Allocare time is given in parentheses. BC:means body contact care; IP: means in proximity care; G means guarding care (see methods for detailed definition); ${ }^{*}$ :Contingency table analysis (Yate's corrections) between high and low energetic stress season. $d f=1$. 
functional hypotheses. These would explain why there is not a coherent explanation of the coming forth of male allocare in non-primate has yet to be realized.

\subsection{Characteristic of male allocare in $R$. bieti at Xiaochangdu, Tibet}

Ross \& MacLarnon (2000) used a 5\% cut-off point to set apart 'intensive male infant caretaking' (IMC) from less intensive forms of male infant care. IMC is not particularly common. It occurs more frequently in monogamous new world species, where the young are relatively heavy compared to the mother's weight, which makes carrying them a difficult task (Schradin \& Anzenberger, 2001). However, IMC is rare in old world primates, except the monogamous siamangs (Hylobates syndactylus), the multi-male Barbary macaques (Macaca sylyanus) (review by Whitten, 1987; Ross \& MacLarnon, 2000) and Tibetan macaques (M. thibetana) (Deng \& Zhao, 1996, Cui \& Zhao, 1999). Mothers of many colobines permit other females to interact with their infants, but male-infant caretaking does not exist (Ross \& MacLarnon, 2000). However, $R$. bieti at Xiaochangdu are notable for a yearly male allocare is $17.2 \%$. According to our results, $R$. bieti at Xiaochangdu belongs to the category of IMC. Unfortunately, lack of individual recognition of the animals and lack of paternity data leave us unable to say anything definite about paternal care or mating; this is to say, we can't say anything on why male prepare to care for the infant.

In spite of similarities in the overall environmental severity, Kirkpatrick (1996) and Kirkpatrick et al (1998) have never registered any cases of male-infant care in $R$. bieti at Wuyapiya within Baimaxueshan Nature Reserve. However, there are anecdotal reports of male-infant care in a southern population of $R$. bieti at Tacheng (Ding, 2003). Unfavorable observation conditions may account for this; they only had 297 hours to observe the monkeys in a whole year observation, with an average observation distance of $400 \mathrm{~m}$ through a field scope.

\subsection{The energetic stress and allocare}

Except for the influence of infant age, female allocare response was positive and male allocare was negative to environmental temperature. These differences mean that the influence of high energetic stress imposed on females may account for allocare patterns. In March and April, females experience a considerable amount of energetic stress for three reasons: firstly, the infant needs to be nursed and carried by the mother; secondly, low ambient temperatures make thermoregulation expenditure increase; thirdly, exiguous food availability makes the situation even worse. Therefore, in the high energetic stress season, female allocare reduced, and this explains why female allocare is lower than that of the low energetic season (Tab. 4). On the contrary, when facing lower energetic stress in June, July and August, female allocare increased even though lactation had not yet ceased and infants were older. Also, females have to give their babies to the crèche despite requiring care (infants are very young) during high energetic stress season. In low energetic season, guarding allocare is decreased and negative to ambient temperature (Tab. 3). Therefore, energetic stresses from harsh environment make females relinquish allocare and male allocare become possible. In spite of male allocare having other functional aims, it is obvious that it would reduce the burden of female. Hence, this will increase the chance of survival of both the female and the infant. This would increase the reproductive success of the female breeder as the predictions of Mitani \& Watts (1997). The finding that male allocare is significantly higher in high energetic stress season (March to April) than that of in low energetic stress season (June to August) is in line with the prediction of energetic stress hypothesis. In March and April, males also meet high energetic stress even though they are free from any nursing activity. Therefore, males also have to adopt a guarding behavior, which is an efficient way to care for many infants at the same time. The fact that the highest male allocare of guarding was exhibited in March and April (Fig. 2a), and male's guarding allocare (Tab. 3) were negative to ambient temperature, further support the hypothesis.

Considering that there is no significant difference in male allocare of body contact and in proximity between high and low energetic seasons (Tab. 4), male allocare must have some other role besides relieving the energetic burden of mothers. We cannot be sure whether this phenomenon supports the hypothesis of "paternal investment" (Taub, 1984), “agonistic buffering” (Deag \& Crook, 1971) or “mating effort" (Smuts, 1985) for testing these hypotheses requires individual recognition (as well as genetic data) of group members, which is difficult to achieve in free-ranging black-and-white snub-nosed monkeys.

\subsection{Male allocare and its evolutionary perspective}

The monogamous siamangs (Hylobates syndactylus), the multimale Barbary macaques (Macaca sylyanus) (review by Whitten, 1987; Ross \& MacLarnon, 2000) and Tibetan macaques (M. thibetana) (Deng \& Zhao 1996, Cui \& Zhao, 1999) are regarded as IMC. The 
monogamous siamang lives in habitat lacking of fruit (Chivers, 1974); both Barbary macaques and Tibetan macaques live in high-latitude/high-altitude habitats, where there is a shortage of fruits (M. s.: Fa, 1984; M. t.: Zhao et al, 1989, 1991). Barbary macaques live in cedar forest (Taub, 1984), which is a harsh environment, and most food items are from oak and cedar trees (Burton, 1972; Deag, 1983; Fa, 1984). Tibetan macaques live at high latitude and high altitude, and face a shortage of fruits in winter as well (Zhao et al, 1989, 1991). For example, the body weight of Tibetan macaque female reduces more than that of the male during the harsh winter (Zhao \& Deng, 1988). The environment at Xiaochangdu is also harsh for its high latitude and high altitude (3500 - $4250 \mathrm{~m}$ asl), and experiences a shortage of food in winter (Xiang et al, 2007b). These four species are all considered to be IMC, in spite of their different social/mating systems, which are monogamous, promiscuous, rank-/age- dependent and mainly OMU, respectively. Energetic stress may be the evolutionary force leading to this pattern, which is forced to face harsh environments. In this way, females have to relinquish infants for energetic stress and male take this interest for another aim. As male allocare may directly increase the mother's freedom to forage, and reduce energetic costs of lactating females in harsh environments, ultimately, benefits would include offspring and whole population viability. It is true that $R$. bieti increase feeding time in high energetic stress season, such as in March, when

\section{References:}

Altman J. 1974. Observational study of behavior: Sampling methods[J]. Behaviour, 49: 227-267.

Chivers DJ. 1974. The Siamang in Malaya:: A field Study of a Primate in Tropical Rain For- Est. Contributions to Primatology, vol 4[M]. Basel: S. Karger 1.

Cui QH, Zhao QK. 1999. Supplementary observation on male-infant behavior in Tibetan macaques at Mount Emei[J]. Zool Res, 20: 196-200.

Deag JM, Crook JH. 1971. Social behaviour and 'agonistic buffering' in the wild Barbary macaque Macaca sylvana[J]. Folia Primatol, 15: $183-200$.

Deng ZY, Zhao QK. 1996. Alloparenting for newborns of Macaca thibetana[J]. Zool Res, 15: 159-165.

Ding W. 2003. Feeding Ecology, Social Organization and Conservation Biology of Rhinopithecus bieti at Tacheng, Yunnan[D]. PhD thesis, Kunming Institute of Zoology, the Chinese Academy of Science.

Ding W, Liu ZH, Grurter CC. 2004. Preliminary information about the social organization of black-and-white snub-nosed monkeys (Rhinopithecus bieti) at Tacheng, China. Asian Primates[J]. Folia Primatol, 75(S1): 371.

Dunbar RM. 1988. Primate Social Systems[M]. London: Chapman and about $52.3 \%$ of daytime was used in feeding, but in July, only $42.2 \%$ was used (Xiang, 2005). However, whether the other species mentioned above increase the feeding time would need to be confirmed in future work.

It would allow us to explore the shaping force of the male allocare of old world monkeys in more detail if similar data were collected in groups of other habitats. We expect the male allocare in the southerner sub-populations (i.e., at Tacheng or Mt. Longmashan) is relatively lower than that of at Xiaochangdu, for its relatively better natural environment. It would be a promising topic for future research to look for environmental correlates/explanations as well. It would also be interesting to determine if male allocare does exist in the closely related sub-nosed monkey (Rhinopithecus roxellana) inhabiting similarly cold environments (Qi et al, 2006), and whether or not it is in line with the energetic stress hypothesis. Also, it is interesting to test if the male allocare is variable with some environmental factors in Barbary macaques and Tibetan macaques, especially if there is a need to meet energetic stress.

Acknowledgements: Thanks are given to the Administrative Bureau of HNNR in Tibet for their support, and Dingzen, Ciren, A'nan and Dengpei for their assistance during in the fieldwork. Special thanks are given to Pro. Zhao Q-K for the idea of this study and Mr. Grueter C-C for English expression of an early draft.

Hall.

Elliot DG. 1912. A Review of Primates[M]/Monographs of the American Museum of National History, Monograph series. Volume III: Anthropoidea, New York: American Museum of Natural History, 103.

Emlen S. 1991. Evolution of Cooperative Breeding in Birds and Mammals[M]/Krebs JR, Davies NB. Behavioural Ecology. 3rd ed. Oxford: Blackwell Scientific, 301-335.

Fa JE. 1984. Habitat distribution and preference in Barbary macaques (Macaca sylvanus)[J]. Int J Primatol, 5: 273-286.

Fa JE. 1986. Use of Time and Resource by Provisioned Troops of Monkeys. Social Behaviour, Time and Energy in the Barbary Macaque (Macaca sylvanus L)[M]. Basel: S. Karger.

Hamilton WD 1964. The genetical evolutional of social behavior[J]. $J$ Theor Biol, 7: 1-51.

Hrdy S. 1976. The care and exploitation of nonhuman primate infants by conspecifics other than the mother [J]. Adv Study Behav, 6: 101-158.

Iwamoto T, Dunbar RM. 1983. Thermoregulation, habitat quality and the behavioural ecology of gelada baboons[J]. J Anim Ecol, 52: 357-366. 
Kirkpatrick RC. 1996. Ecology and Behavior of the Yunnan Snub-nosed Langur (Rhinopithecus bieti, Colobinae)[D]. Ph.D. thesis, Univ. of California, Davis.

Kirkpatrick RC, Long YC, Zhong T, Xiao L. 1998. Social organization and range use in the Yunnan snub-nosed monkey Rhinopithecus bieti[J]. Int J Primat, 19: 13-51.

Kleiman D. 1977. Monogamy in mammals[J]. Q Rev Biol 52: 36-69.

Long YC, Kirkpatrick RC, Zhong T, Xiao L. 1994. Report on the distribution, population, and ecology of the Yunnan snub-nosed monkey (Rhinopithecus bieti) [J]. Primates 35: 241-250.

McKenna JJ. 1979. The evolution of allomothering behavior among colobine monkeys: function and opportunism in evolution[J]. $A m$ Anthropol, 81: 818-840.

Ménard N, von Segesser F, Scheffrahn Pastorini J, Vallet D, Gaci B, Martin RD, Gautier-Hion A. 2001. Is male-infant caretaking related to paternity and/or mating activities in wild Barbary macaques (Macaca sylvanus)?[J]. Compt Rendus Acad Sci III Sci Vie, 324: 601-610.

Mitani JC, Watts D. 1997. The evolution of non-maternal caretaking among anthropoid primates: do helpers help? [J]. Behav Eco Sociobiol, 40: 213-220.

Nakayama T, Hori T, Nagasaka T, Tokura H, Tadaki E. 1971. Thermal and metabolic response in the Japanese monkey at temperatures of 5-38 ${ }^{\circ}$ C [J]. J Appl Physiol, 31: 332-351

Nicolson NA. 1987. Infants, mothers, and other females [M]// Smuts BB, Cheney DL, Seyfarth RM, Wrangham RW, Struhsaker TT. Primate Societies. United States: University of Chicago Press, 330-342.

Paul A, Preuschoft S, van Schaik CP. 2000. The Other Side of the Coin: Infanticide and the Evolution of Affiliative Male-Infant Interactions in Old World Primates [M]// van Schaik CP, Janson $\mathrm{CH}$. Infanticide by Males and Its Implications. UK: Cambridge: University Press, 269-292.

Qi XG, Li BG, Li YH. 2006. Maternal investment and birth sex ratio bias of the golden snub-nosed monkey Rhinopithecus roxellana in Qinling Mountains of China[J]. Acata Zool Sin, 52: 1-10.

Quiatt D. 1979. Aunts and mothers: adaptive implications of allomaternal behavior of nonhuman primates[J]. Am Anthropol, 81: 311-319.

Riedman ML. 1982. The evolution of alloparental care and adoption in mammals and birds[J]. $Q$ Rev Biol, 57: 405-435.

Ross C, MacLarnon A. 2000. The evolution of non-maternal care in anthropoid primates: A test of the hypotheses[J]. Folia Primatol, 71: 93-113.

Schradin C, Anzenberger G. 2001. Costs of infant carrying in common marmosets (Callithrix jacchus): An experimental analysis[J]. Anim Behav, 62: 289-295.

Smuts BB. 1985. Sex and Friendship in Baboons[M]. Venice: Aldine Press.
Sommer V. 1989. Infant MistrEatment in Langur Monkeys: Sociobiology from the Wrong End?[M]// Rasa A, Vogel C, Voland E. The Sociobiology of Sexual and Reproductive Strategies. London: Chapman Hall, 100-127.

Stanford CB. 1992. Costs and benefits of allomothering in wild capped langures (Presbytis pileata) [J]. Behav Ecol Sociobiol, 30: 29-34.

Taub DM. 1984. Male Caretaking Behavior Among Wild Barbary Macaques (Macaca sylvanus) [M]// Taub DM. Primate Paternalism. New York: Van Nostrand Reinhold, 20-55.

Taylor CR, Heglund NC, Maloy GMO. 1982. Energetics and mechanics of terrestial locomotion. I. Metabolic energy consumption as a function of speed and body size in birds and mammals[J]. J Exp Biol, 97: 11-21.

van Schaik CP, Paul A. 1996. Male care in primates: Does it ever reflect paternity?[J]. Evol Anthropol, 5: 152-156.

Whitten PL. 1987. Infants and adult males[M]//Smuts BB, Cheney DL, Seyfarth RM, Wrangham RW, Struhsaker TT. Primate Societies. Chicago: University of Chicago Press, 343-357.

Xiang ZF. 2005. The ecology and behavior of black-and-white snub-nosed monkeys (Rhinopithecus bieti, Colobinae) at Xiaochangdu in Honglaxueshan National Natural Reserve, Tibet, China[D]. PhD thesis, Kunming Institute of Zoology, the Chinese Academy of Science.

Xiang ZF, Huo S, Wang L, Cui LW, Xiao W, Quan RC, Zhong T. 2007a. Distribution, status and conservation strategies of the black-and-white snub-nosed monkey Rhinopithecus bieti in Tibet[J]. Oryx, 41(4): 525-531.

Xiang ZF, Huo S, Xiao W, Quan RC, Grueter CC. 2007b. Diet and feeding behavior of Rhinopithecus bieti at Xiaochangdu, Tibet: Adaptations to a marginal environment[J]. Am J Primat, 69: 1141-1158.

Xiang ZF, Sayers K, Grueter CC. 2009. Direct paternal care in black-and-white snub-nosed monkeys[J]. J Zool, 278: 157-162.

Xiang ZF, Sayers K. 2009. Reports on seasonality of mating and birth events in wild black-and-white snub-nosed monkeys (Rhinopithecus bieti) at Xiaochangdu, Tibet[J]. Primates, 50: 50-55.

Zar JH. 1999. Biostatistical Analysis [M]. $4^{\text {th }}$ ed London: Prentice-hall Inc.

Zhao QK, Deng ZY. 1988. Macaca thibetana at Mt. Emei, China: I: A cross-sectional study of growth and development[J]. Am J Primat, 16: $251-260$.

Zhao QK, Deng ZY, Xu JM. 1991. Natural foods and their ecological implication for Macaca thibetana at Mt. Emei, China[J]. Folia Primatol, 57: 1-15.

Zhao QK, Xu JM, Deng ZY. 1989. Climate, vegetation and topography of the slope habitat of Macaca thibetana at Mt. Emei, China[J]. Zool Res, 10 (suppl.): 91-100. 